\title{
Simulation of burning velocities in gases vented from thermal run- a-way lithium ion batteries
}

\author{
Jonathan Johnsplass, Mathias Henriksen, Knut Vågsæther, Joachim Lundberg and \\ Dag Bjerketvedt \\ University College of Southeast Norway, Porsgrunn, Norway, knutv@usn . no
}

\begin{abstract}
This paper describes the results from simulations of laminar burning velocities in the premixed air and flammable gases vented from abused Li-ion batteries. The released mixture from such batteries contain mixtures of hydrogen, methane, ethylene, carbon monoxide and carbon dioxide. The study also includes the combustion properties of an electrolyte, dimethyl carbonate. The simulation results show the laminar burning velocities as a function of concentration, pressure and temperature for the gas mixtures and electrolyte. The goal of the present project is to use the simulated burning velocities in curve fitted functions for use in computational fluid dynamics (CFD) codes.
\end{abstract}

Keywords: $\quad$ Li-ion battery, Safety, Laminar burning velocity

\section{Introduction}

In the recent years, we have seen a strong increase in the use of $\mathrm{Li}$ ion batteries as an energy carrier in the transport sector. This growth is expected to continue in future transport applications on road, rail, and sea. The advantage of Li ion batteries is the relatively high energy density. However the high energy density also represents a hazard. If the battery experiences a thermal run-a-way or overheating it might vent combustible gases, mists and particles which can cause fires or explosions. Such an explosion occurred in Sweden in 2016 during a Li-ion battery test.

Harris et al. (2009) studied the impact from the carbonate solvents used in $\mathrm{Li}$-ion batteries where they reported that flames of carbonate solvents are less energetic than hydrocarbons as propane.

Most lithium-ion studies are primarily focused on the gases vented from the batteries, the other phases are neglected. The study by Ponchaut et al. (2014) studied two combustion properties, the deflagration index and the overpressure at constant volume combustion of the vented gases from two lithium-ion pouch batteries. The study concludes that the gases vented from the li-ion pouch battery are comparable to the hydrocarbons methane, and propane, but that vented gas have a broader combustion range, due to the presence of hydrogen, and carbon monoxide.

In order to make a risk assessment and consequence analysis we need to know the combustion properties of the gases involved. Such information is lacking in the open literature today. There are two ways of finding that type of information; one way is to carry out experimental investigations the other is to perform simulations. In this paper we describe the simulation approach using the open-source chemical kinetics software Cantera.

The overall objective of this activity is to develop a CFD (Computational Fluid Dynamics) tool for simulation of dispersion and combustion of gas, mist and particles emitted from abused Li-ion batteries. The present paper presents the first part of this activity, which is to simulate the laminar burning velocity of the different mixtures. In order to find these coefficients we use the Cantera program (Goodwin et al, 2017) to simulate the laminar burning velocities and the thermodynamic properties of the combustion products for different stoichiometry, initial pressure and temperature. The planned path from these simulated velocities is to use a Python LMFIT non-linear optimization program to find the fitted functions to be used in the CFD software. The route from Cantera simulations to the CFD simulation is illustrated in figure 1 . The aim of presented paper is to show the method and the results of the simulation of the burning velocity as a function of stoichiometry (equivalent ratio), pressure and temperature. 


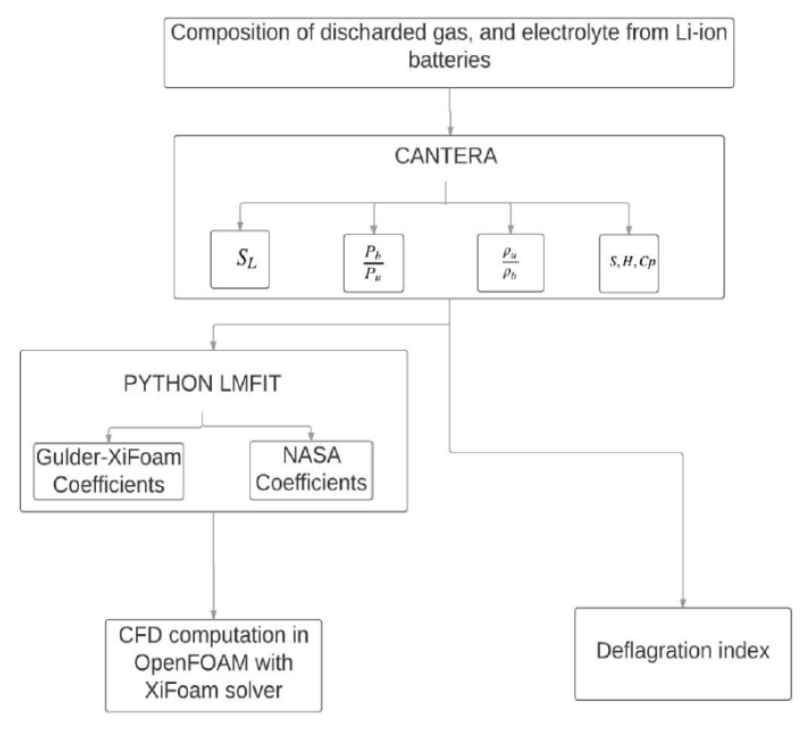

Figure 1. The planned activity path from simulated burning velocities to CFD simulations.

\section{Materials and Methods}

In this section we describe the Cantera program and the reaction mechanisms that we used to simulate the laminar flames for the different pre-mixed gas mixtures. The following subsections describe the flammable substances we have studied; i) gas composition emitted from $18650 \mathrm{Li}$-ion batteries, ii) dimethyl carbonate electrolyte and iii) methane, propane and hydrogen.

\subsection{Cantera Software}

Cantera 2.3.0 is an open-source software (Goodwin et $a l, 2017)$ for simulations of thermodynamic states, homogeneous and heterogeneous chemistry, chemical equilibrium, reactor networks, steady 1-D flames, reaction path diagrams, non-ideal equations of state and electrochemistry. It can easily be used as plugin or toolbox in Python and Matlab.

\section{2 reaction mechanisms}

We used the laminar flame model in Cantera 2.3.0 which takes into account the multi-component heat and mass transfer, convective transport and elementary chemical reactions. The $\mathrm{K}+2$ conservation equations below have to be solved to find the laminar burning velocity, $S_{L}$. Where K is the number of species. Equation (1) is the continuity equation, equation (2) is the mass conservation of each specie and equation (3) is the conservation equation for energy.

$$
\begin{gathered}
\dot{m}=\rho u A=\rho_{0} S_{L} A \\
\dot{m} \frac{d Y_{k}}{d x}+\frac{d}{d x} \rho Y_{k} V_{k}+A \dot{\omega} W_{k}=0 \\
\dot{m} \frac{d T}{d x}-\frac{1}{c_{p}} \frac{d}{d x}\left(\lambda A \frac{d T}{d x}\right) \\
+\frac{A}{c_{p}} \sum_{k=1}^{K}\left(\rho Y_{k} V_{k} c_{p, k} \frac{d T}{d x}+\dot{\omega}_{k} h_{k} W_{k}\right)=0
\end{gathered}
$$

Where, $\dot{m}$ is the mass flow, $\rho$ is the density, $u$ is the flow velocity, $Y_{k}$ is the mass fraction of specie $\mathrm{k}, V_{k}$ is the diffusion velocity of specie $\mathrm{k}, \dot{\omega}_{k}$ is the reaction rate of specie $\mathrm{k}, W_{k}$ is the molecular weight of specie $\mathrm{k}, T$ is the temperature, $c_{p}$ is the specific heat capacity, $\lambda$ is the heat conductivity, A is the cross sectional area, $h_{k}$ is the specific enthalpy of specie $\mathrm{k}$.

The reaction rate of specie $\mathrm{k}$ is calculated from the elementary reaction mechanism, which is solved as shown in equation 4. Equation 5 is the Arrhenius rate constant.

$$
\begin{gathered}
\dot{\omega}_{k}=\sum_{j=1}^{J} k_{j} \prod_{i=1}^{I} c_{i}^{v_{i}} \\
k_{j}=A_{j} T^{\beta_{j}} \exp \left(\frac{-E_{a, j}}{R T}\right)
\end{gathered}
$$

Where: $\mathbf{J}$ is the the elementary reactions containing specie $\mathrm{k}, k_{\mathrm{j}}$ is the rate konstant for reaction $\mathrm{j}$, I is the number of reactants in reaction $\mathrm{j}, \mathrm{c}$ is the molar concentration of the reactants, $v$ is the stoichiometric index of component $\mathrm{i}, \mathrm{A}_{\mathrm{j}}$ is the pre-exponential factor, $\beta$ is the temperature index, $E_{a}$ is the activation energy. The three constants in the Arrhenius rate constant are found in the reaction mechanism.

\subsection{Reaction Mechanisms}

To calculate the reaction rates we use Cantera 2.3.0 with the GRI-Mech 3.0 mechanism (Gregory et al). The mechanism has 325 reactions and 53 species. It is optimized for natural gas combustion, i.e. $\mathrm{CH}_{4}$, but includes several other species, e.g. $\mathrm{H}_{2}, \mathrm{CO}, \mathrm{C}_{2} \mathrm{H}_{4}$ and $\mathrm{C}_{2} \mathrm{H}_{6}$. GRIMech3.0 is the only default reaction mechanism in Cantera which includes all the relevant species from the Liion vented gas. We have therefore chosen GRI-Mech 3.0 for all simulation except for the dimethyl carbonate (i.e. DCM) simulations. 
For the dimethyl carbonate electrolyte, we used the reaction mechanism of Glaude et al 2004 with 805 reactions and 102 species

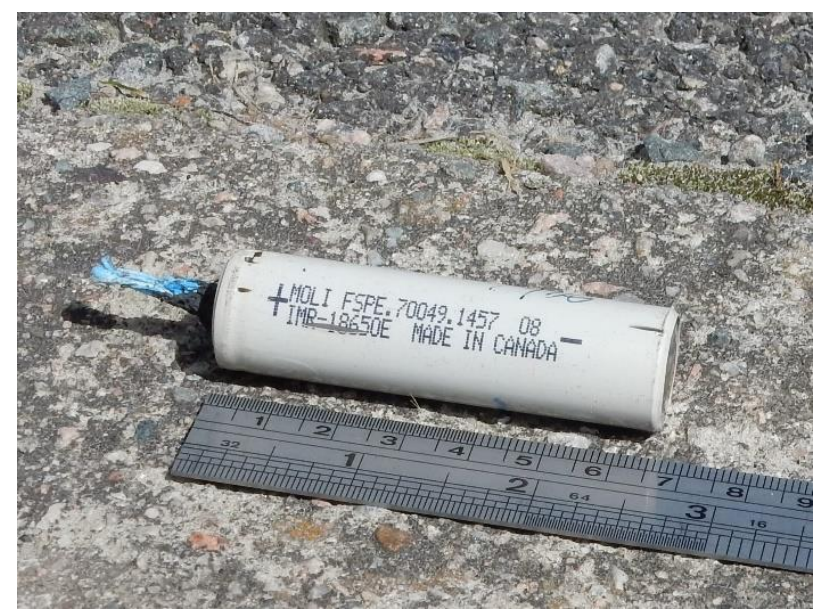

Figure 2. Picture of an $18650 \mathrm{Li}$-ion battery after a rupture test.

\subsection{Gas Composition emitted from Li ion batteries}

Golubkov et al, (2014) analyzed the gas composition of the vented gas emitted from three different 18650 batteries, i.e. an LCO (Lithium Cobalt Oxide: $\mathrm{LiCoO} 2$ ), NMC (Lithium Nickel Manganese Cobalt Oxide: LiN$\mathrm{iMnCoO} 2$ ) and LFP (Lithium Iron Phosphate: LiFePO4) lithium-batteries. Table 1 gives the specifications for the three $\mathrm{Li}$-ion batteries. We should notice that these batteries contain flammable materials in form of $\mathrm{Li}$, electrolytes and graphite. When an 18650 battery is overheated or experiences a thermal run-a-way the pressure inside the battery will increase. If the battery reaches around $150^{\circ} \mathrm{C}$ a rupture disc will open and relief the pressure and combustible gases, mists and possible particles will then be vent into the surrounding atmosphere. Figure 2 shows a picture of an 18650 battery.
Table 1. Specfications of three different types of Li-ion batteries.

\begin{tabular}{|c|c|c|c|c|}
\hline Property & Variable & LCO & LNMCO & LFP \\
\hline Cell mass & g & 44.3 & 43.0 & 38.8 \\
\hline Capacity & Ah & 2.6 & 1.5 & 1.1 \\
\hline $\begin{array}{l}\text { Minimum } \\
\text { voltage }\end{array}$ & $\mathrm{V}$ & 3.0 & 3.0 & 2.5 \\
\hline $\begin{array}{l}\text { Maximum } \\
\text { voltage }\end{array}$ & v & 4.2 & 4.1 & 3.5 \\
\hline $\begin{array}{l}\text { Electrolyte } \\
\text { solvents }\end{array}$ & & DMC:EMC:EC $(6: 2: 1)^{3}$ & $\begin{array}{l}\text { DMC:EMC:EC:PC } \\
(7: 1: 1: 1)\end{array}$ & $\begin{array}{l}\text { DMC:EMC:EC:PC } \\
(4: 2: 3: 1)\end{array}$ \\
\hline $\begin{array}{l}\text { Cathode } \\
\text { material }\end{array}$ & & $\begin{array}{l}\mathrm{LiCoO}_{2}: \\
\mathrm{Li}\left(\mathrm{Ni}_{0.5} \mathrm{Mn}_{0.25} \mathrm{Co}_{0.25}\right)_{2} \\
(2: 1)\end{array}$ & $\begin{array}{l}\mathrm{Li}\left(\mathrm{Ni}_{0.5} \mathrm{Mn}_{0.25} \mathrm{Co}\right. \\
0.10) \mathrm{O}_{2}\end{array}$ & $\mathrm{LiFePO}_{4}$ \\
\hline $\begin{array}{l}\text { Anode } \\
\text { material }\end{array}$ & & Graphite & Graphite & Graphite \\
\hline
\end{tabular}

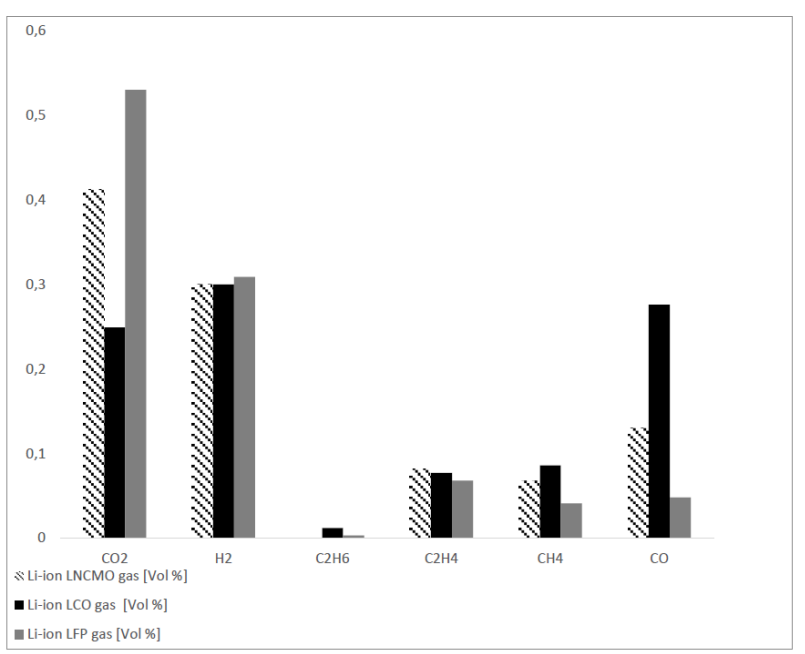

Figure 3. The composition of the emitted gas from three different Li-ion batteries.

Golubkov et al. used a GC to quantified composition of the vented gas. The result from the measurements is shown in Figure 3. For all the three batteries the $\mathrm{H}_{2}$ content was around $30 \%$. The emitted gas contains also significant amounts of combustible hydrocarbons in form of ethylene, $\mathrm{C}_{2} \mathrm{H}_{4}$, and methane, $\mathrm{CH}_{4}$. The sum of $\mathrm{CO}_{2}$ and $\mathrm{CO}$ was more or less constant, but the $\mathrm{CO}_{2}$ and $\mathrm{CO}$ concentration vary for the three cases. The LCO battery gave nearly $30 \%$ CO while LFP gave less than $5 \%$.

\section{Results and Discussions}

The present simulations are for air mixtures with DMC, hydrogen, methane and ethylene. The hydrogen, methane and ethylene included as reference fuels.

\subsection{Burning Velocity vs. Equivalence Ratio}


Figures 4 and 5 show the laminar burning velocity as a function of equivalence ratio for initial condition $1 \mathrm{~atm}$ and $298.15 \mathrm{~K}$. The equivalence ratio, $\varphi$, is the fuel-to-air ratio to the stoichiometric fuel-to-air ratio. For an equivalence ratio less than one (i.e. $\varphi<1$ ), the fuel-air mixture is fuel lean and we have an excess of air (or oxidizer). For $\varphi>1$, the mixture is fuel rich. It is evident from that the maximum burning velocity is slightly on the rich side for all components, i.e. when $\varphi>1$.

Except for pure $\mathrm{H}_{2}$ the maximum laminar burning velocities are in the range of $0.35-0.65 \mathrm{~m} / \mathrm{s}$. Hydrogen however, has a maximum laminar burning velocity of 3 $\mathrm{m} / \mathrm{s}$. This value reflects the high reactivity and the high thermal diffusivity of $\mathrm{H}_{2}$. The two other reference fuels gave maximum laminar burning velocities of $0.45 \mathrm{~m} / \mathrm{s}$ for propane and $0.38 \mathrm{~m} / \mathrm{s}$ for methane, which is typical values for gaseous hydrocarbons. We found that the electrolyte component; dimethyl carbonate (DMC) had maximum laminar burning velocity in the same range as methane but with higher burning velocities on the rich side. The Li-ion LFP gas and methane are also similar with respect to laminar burning velocity.

The Li-ion LCO gas shows a higher laminar burning velocity than the other gasses at a maximum of $0.65 \mathrm{~m} / \mathrm{s}$ at equivalence ratio at 1.28 . The simulation of $S_{L}$ for LCO gas gave the highest $S_{L}$ when we exclude $\mathrm{H}_{2}$. This high $S_{L}$ for the Li-ion LCO gas is likely due to the low $\mathrm{CO}_{2}$ content and high $\mathrm{CO}$ content in the gas mixture.

Li-ion LNCMO gas propagates at the same burning velocity as propane.

We also observe that the $\mathrm{CO}$ content in the emitted gas has a significant influence on the laminar burning velocity.

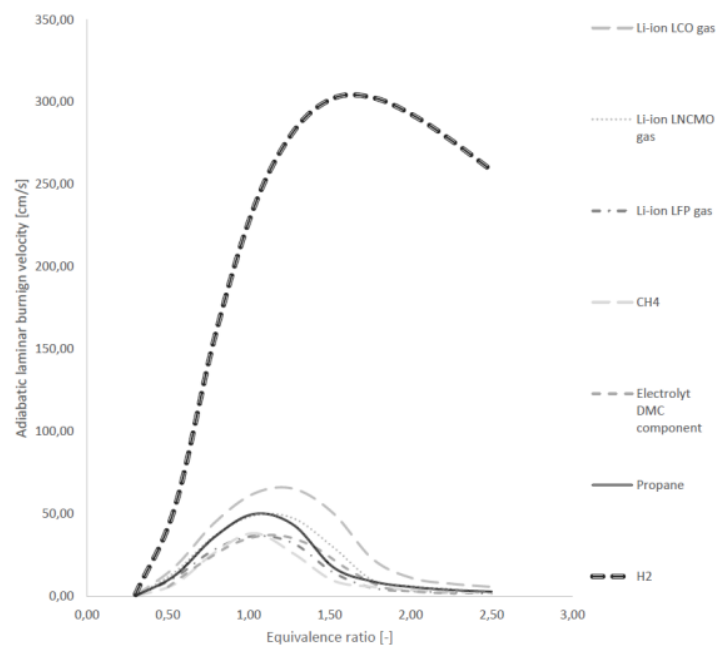

Figure 4. Comparison of the laminar burning velocity of the discharged gas emitted from an LCO, LNCM, and an LFP battery premixed with air, dimethyl carbonate-air and methane-air at initial conditions of $1 \mathrm{~atm}$, and $298.15 \mathrm{~K}$, were the burning velocity is a function of equivalence ratio.

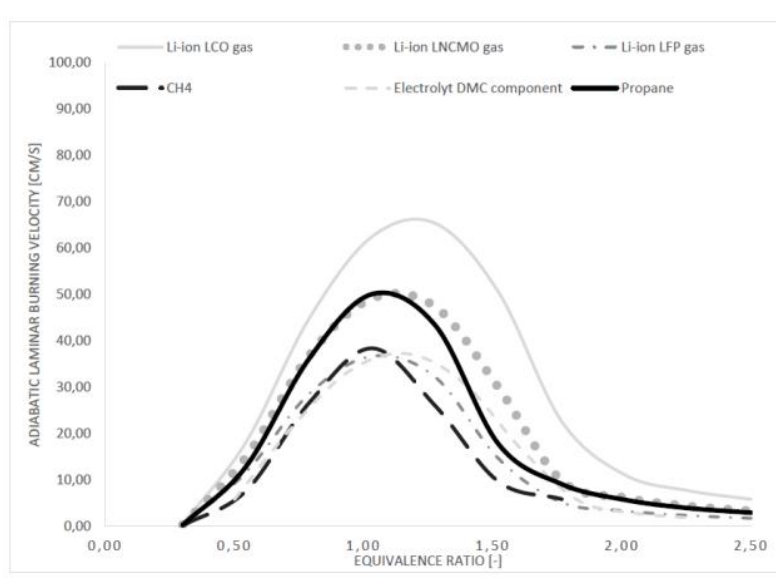

Figure 5. Comparison of the laminar burning velocity of the discharged gas emitted from an LCO, LNCM, and an LFP battery premixed with air, electrolyte component dimethyl carbonate-air and methane-air at initial conditions of $1 \mathrm{~atm}$, and $298.15 \mathrm{~K}$, were the burning velocity is a function of equivalence ratio.

\subsection{Burning Velocity vs. Initial Pressure}

Figure 6 shows the laminar burning velocity, $S_{L}$, for stoichiometric mixtures at $298 \mathrm{~K}$ and initial pressure from 0.5 to 10 bar. The burning velocity, in general, decreases with the pressure rise for all the Li-ion battery mixtures. However, the burning velocity for hydrogen has a peak at 2.25 bar. Even though the gas from the Li-ion LCO, LNCMO and LFP batteries constitute approximately of $30 \%$ hydrogen this does not seem to cause the pressure dependency for the burning velocity of the gaseous mixtures to behave as a pure hydrogen-air mixture. The pressure dependency for the burning velocity is equal to the Li-ion battery gases, and the electrolyte component; dimethyl carbonate.

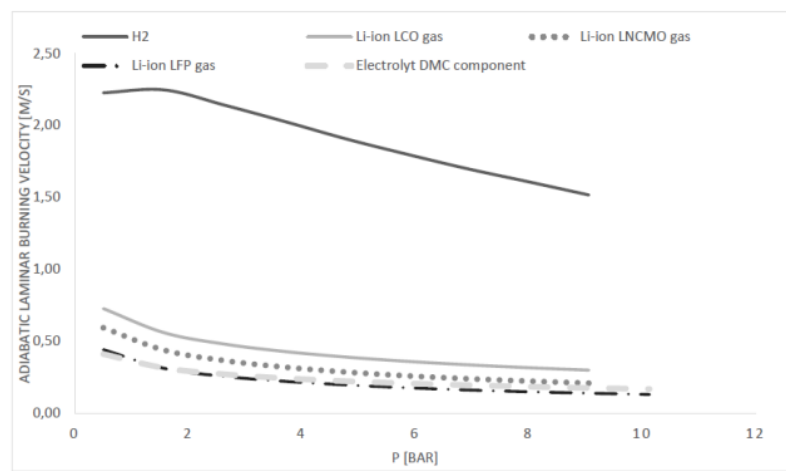

Figure 6. Comparison of the laminar burning velocity of the discharged gas emitted from an LCO, LNCM, and an LFP battery premixed with air, dimethyl carbonate-air and methane-air at initial conditions of $298.15 \mathrm{~K}$, were the burning velocity is a function of the initial pressure in bar.

\subsection{Burning Velocity vs. Initial Temperature}

Figure 7 shows the laminar burning velocity, $S_{L}$, for stoichiometric mixtures at 1 bar and initial temperature from 
250 to $950 \mathrm{~K}$. The laminar burning velocity is a strong function of the initial temperature of the reactants. The gases from the $\mathrm{Li}$-ion batteries are behaving uniformly; the velocity is steadily increasing from $250 \leq \mathrm{T} \leq 950$ with a very rapid increase at $\mathrm{T}=950 \mathrm{~K}$. For the purpose of this study, temperatures below $650 \mathrm{~K}$ is the most interesting. The sudden increase in burning velocity at 950 $\mathrm{K}$ is probably because the mixture is close to the auto ignition temperature.

The electrolyte component; dimethyl carbonate, is less sensitive to temperature compared to the vented gases from the Li-ion batteries.

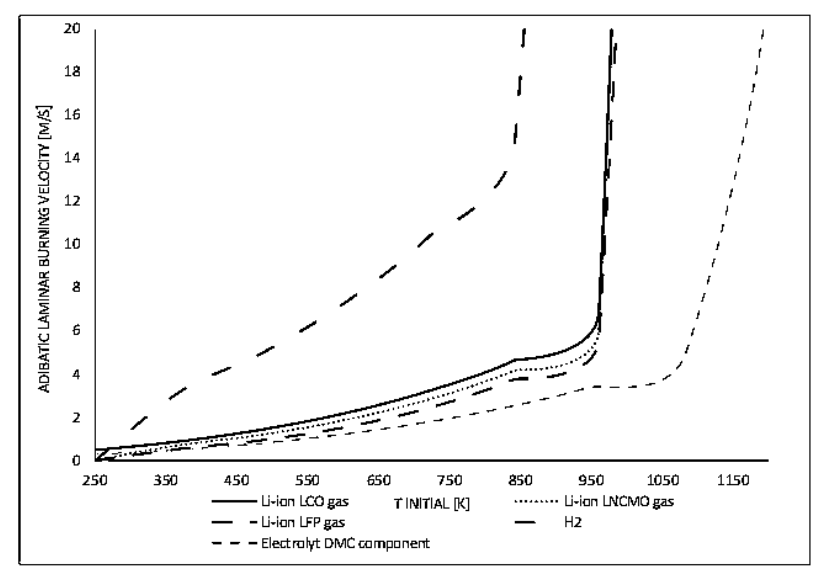

Figure 7. Comparison of the laminar burning velocity of the discharged gas emitted from an LCO, LNCM, and an LFP battery premixed with air, and methane-air at initial conditions of $1 \mathrm{~atm}$, were the burning velocity is a function of the initial temperature in Kelvin.

\section{Conclusion}

We have simulated the laminar burning velocity for three gas mixtures vented from thermal runaway lithium batteries, one electrolyte and three reference fuels. The laminar burning velocities for these gases are similar to methane or even higher. This finding is important knowledge and will be used as input to computational fluid dynamics (CFD) codes for simulating gas explosions. To our knowledge these data is unique. The Cantera software has proven to be a useful tool for estimation of the laminar burning velocities for gas vented from Li-ion batteries and dimethyl carbonate electrolyte, DCM.

The emitted gas from Li-ion batteries and the DMC electrolyte, when mixed with air, burns at flame speeds similar to hydrocarbons such as methane and propane.

The burning velocity for all mixtures is decreasing for elevated initial pressure and increases for elevated temperature.

It is clear from our simulations that the gas vented from a thermal runaway in a $\mathrm{Li}$ ion battery burns comparable to methane and propane. These gases will therefore under certain conditions, such as confinement and obstructed areas, represent a serious hazard with regard to explosions and fires.

\section{Acknowledgements}

This work is part of an activity on safety in the MoZEES project (www.mozees.no), a Norwegian national center for environment friendly energy research (NFR-FME) with a focus on battery and hydrogen technology for transport applications. This paper is based on a M.Sc. thesis at USN.

\section{References}

Glaude, P. A., W. J. Pitz, and M. J. Thomson, "Chemical Kinetic Modeling of Dimethyl Carbonate in an Opposed-Flow Diffusion Flame," Proceedings of the Combustion Institute 30, pp. 1095-1102 (2004); Lawrence Livermore National Laboratory, Livermore, CA, UCRL-JC-201358.

Golubkov, A. W., Fuchs, D., Wagner, J., Wiltsche, H., Stangl, C., Fauler, G. \& Hacker, V. (2014). Thermal-runaway experiments on consumer Li-ion batteries with metal-oxide and olivin-type cathodes. RSC Advances, 4(7), 3633-3642.

Goodwin, D. G., Moffat, H. K., and Speth, R. L.. Cantera: An object- oriented software toolkit for chemical kinetics, thermodynamics, and transport processes. http://www.cantera.org, 2017. Version 2.3.0. doi:10.5281/zenodo.170284

Gregory P. Smith, David M. Golden, Michael Frenklach, Nigel W. Moriarty, Boris Eiteneer, Mikhail Goldenberg, C. Thomas Bowman, Ronald K. Hanson, Soonho Song, William C. Gardiner, Jr., Vitali V. Lissianski, and Zhiwei Qin http://www.me.berkeley.edu/gri_mech

Harris, S. J., Timmons, A., \& Pitz, W. J. (2009). A combustion chemistry analysis of carbonate solvents used in Li-ion batteries. Journal of Power Sources, 193(2), 855-858.

Ponchaut NF, Colella F, Spray R, Horn Q. Thermal management modeling for avoidance of thermal runaway conditions in lithium-ion batteries. SAE Technical Paper, 2014. 